\title{
The Impact of Thermal Performance on The Roof Surface to EnERgy EFFicient of High-Rise BuILding In The Tropical Region
}

\author{
Pengaruh KinerJa Thermal pada Permukaan atap \\ TERHADAP EFISIENSI ENERGI BANGUNAN TINGgi DI DAERAH TROPIS
}

\author{
Sri Yuliani ${ }^{1 *}$, Wiwik Setyaningsih ${ }^{2}$ \\ Department of Architecture, Engineering Faculty, Universitas Sebelas Maret ${ }^{1}$ \\ sriyuliani71@staff.uns.ac.id * \\ Department of Architecture, Engineering Faculty, Universitas Sebelas Maret $^{2}$
}

\begin{abstract}
The surface temperature of the building material may release a heat load in the micro-environment. The largest building envelope receives the heat load of solar radiation is the roof. The strategic roof position at the top of the building has the opportunity to radiate heat received into the environment. Heat emissions lead to rising temperatures, so it is necessary to lower the temperature in microenvironment. When the heat of the building is not lowered will lead to an increase in the urban heat island (UHI). The objective of the study was to find the relationship between the thermal performance of the roof of the building and the energy efficiency in the high-rise building, in order to establish efficient thermal comfort. The research method uses experimental way in real model which is in Surakarta City, as humid tropical climate area. The result of the study is a comparison of the heat performance of three roofing materials which would later recommend the criteria of energy efficient roof for high buildings.
\end{abstract}

Keywords: thermal performance, roof surface, energy eficient, high-rise building

\section{PENDAHULUAN}

Potret konsumsi energi di dunia banyak dipengaruhi oleh tiga sektor yakni transportasi, pembangunan dan industri. Sektor pembangunan diantaranya berhubungan dengan pembangunan gedung dan karya-karya arsitektur. Bangunan gedung terutama bangunan tinggi banyak menggunakan energi secara terus-menerus dalam operasional bangunan. Konsumsi energi pada operasional bangunan tinggi yang banyak menggunakan energi listrik dalam jumlah besar diantaranya untuk memenuhi kebutuhan penyediaan kenyamanan bangunan yakni untuk menghidupkan AC, penerangan dan sirkulasi vertikal bangunan. Penggunaan AC merupakan kebutuhan yang paling besar bahkan dapat mencapai $60 \%$ dari jumlah keseluruhan konsumsi listrik pada bangunan.

Sebuah bangunan dapat menyumbangkan dampak terbesar pada kerusakan lingkungan alam. Penyebabnya karena ada tiga hal yakni bangunan akan menyerap energi yang besar, bangunan membutuhkan banyak sumber bahan material yang diambil dari lingkungan, dan bangunan yang nantinya digunakan oleh kegiatan manusia secara alami akan menghasilkan sampah kegiatan, pengurangan area peresapan bahkan memberikan dampak peningkatan panas lingkungan sebesar 30-40\% di area sekitarnya. Dalam sebuah seminar tentang Green Architecture tahun 2013 di Jakarta, dinyatakan bahwa energi yang digunakan untuk bangunan semakin lama 
semakin naik dan menjadi paling besar mengkonsumsi energi dunia di banding sektor lain (Suryabrata, 2013). Secara detail dijelaskan bahwa sektor pembangunan gedung mengungguli sektor transportasi dan industri, bahkan semakin lama menunjukkan angka yang semakin tinggi. Sementara energi yang dibutuhkan untuk sektor transportasi justru menunjukkan upaya efisiensi yang cukup signifikan dibandingkan dengan sektor pembangunan gedung dan industri, seperti pada gambar 1. Hal ini tentu perlu segera direspon dengan peluang pemanfaatan riset dan implementasinya tentang pengelolaan bangunan agar lebih efisien dalam penggunaan energi.

\section{Building energy consumptions}

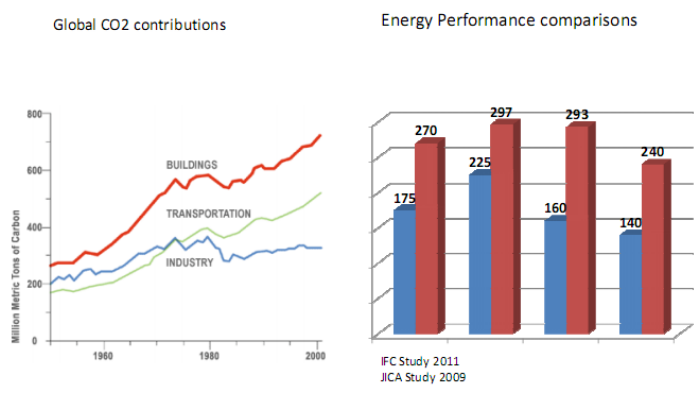

Gambar 1. Potret konsumsi energi sektor pembangunan gedung, transportasi dan industri. Sumber: (Suryabrata, 2013)

Bangunan tinggi yang memiliki desain akomodatif terhadap potensi lingkungan tropis dengan ciri khas matahari berlimpah dan kecepatan angin sepoi-sepoi, secara hipotesis dapat memberikan tingkat kenyamanan huni yang lebih baik. Sehingga, perlu upaya mengoptimalkan potensi lingkungan alam untuk mendukung tercapainya kenyamanan fisik bangunan dan kawasan. Upaya ini diperlukan terutama di daerah lingkungan berkepadatan tinggi di perkotaan dan pinggiran kota.

Pengkondisian udara pada bangunan tinggi dapat diselenggarakan melalui sistem pendinginan pasif agar penggunaan energi bangunan dapat lebih efisien. Salah satu desain pasif yakni pemilihan bahan selubung bangunan dari atap, dinding, interior dan eksterior.

Penelitian ini fokus pada bagian atas bangunan, yang merupakan bagian terbesar yang mendapat beban panas radiasi matahari. Tujuan penelitian menemukan hubungan bahan selubung atap terhadap efisiensi energi bangunan tinggi. Teori penurunan suhu dalam urban heat island (UHI) tidak hanya mengatur jarak kepadatan bangunan, aktivitas bangunan, namun juga dapat melalui penggunaan sistem pendinginan pasif bangunan dengan mengaplikasikan konsep arsitektur ekologis dengan memanfaatkan potensi lingkungan iklim tropis guna menyediakan iklim mikro yang lebih sehat dan berkualitas. Penerapan prinsip arsitektur ekologis dapat diimplementasikan pada beberapa aspek perancangan yakni: konfigurasi bentuk bangunan, orientasi, fasade dan bukaan, sumber energi lingkungan, material bahan bangunan dan kontrol terhadap lingkungan (Utami, Yuliani, \& Mustaqiemah, 2017)

Pengaruh yang signifikan terhadap penurunan penggunaan energi listrik pada operasional AC untuk kenyamanan bangunan tinggi dan penurunan suhu lingkungan mikro akan memberikan nilai efisisensi energi bangunan. SNI tentang konservasi energi selubung bangunan pada bangunan gedung, memformulasikan bahwa nilai efisiensi energi bangunan yang dipresentasikan dengan nilai EEI, yaitu membandingkan luasan ruang bangunan berAC dan ruang yang tidak menggunakan AC. Nilai EEI sebagai indikasi efisiensi energi suatu bangunan. Selain EEI, juga ada faktor selubung bangunan yang diperhitungkan dalam penentu efisiensi energi yakni melalui formulasi RTTV dan OTTV (SNI, 2000). RTTV adalah Roof Thermal Transfer Value, yakni nilai perpindahan panas bangunan bagian atap ke lingkungan sekitar. Sedangkan OTTV merupakan Overall Thermal Trasnfer Value, yakni menghitung seluruh bahan pada komponen dinding bangunan. Bangunan hemat energi memiliki kriteria OTTV sebesar maksimal kurang dari 45 Watt $/ \mathrm{m}^{2}$. Secara umum, RTTV dan OTTV sangat dipengaruhi oleh krieria bahan selubung bangunan. Dalam SNI 03-5389-2000 formulasi menghitung RTTV melalui persamaan berikut ini:

$\mathrm{RTTV}=\frac{\alpha\left(A_{t} x U_{t} x T D_{E k} E k\right)+\left(A_{S} x U_{S} x \Delta T\right)+\left(A_{S} x S C x S F\right)}{A_{0}} \ldots[1]$ dimana, 


\begin{tabular}{|c|c|}
\hline RTTV & $\begin{aligned}= & \text { Nilai perpindahan thermal atap } \\
& \text { yang memiliki arah atau } \\
& \text { orientasi tertentu }\left(\mathrm{Watt} / \mathrm{m}^{2}\right)\end{aligned}$ \\
\hline A & Absorbtansi radiasi matahari \\
\hline$A_{t}$ & $=\begin{array}{l}\text { Luas atap yang tidak tembus } \\
\text { cahaya }\left(\mathrm{m}^{2}\right)\end{array}$ \\
\hline$A_{s}$ & $=$ Luas skylight $\left(\mathrm{m}^{2}\right)$ \\
\hline $\mathrm{U}_{\mathrm{t}}$ & $\begin{aligned}= & \text { Transmitansi thermal atap tak } \\
& \text { tembus cahaya }\left(\text { Watt } / \mathrm{m}^{2} . \mathrm{K}\right)\end{aligned}$ \\
\hline $\mathrm{TD}_{\mathrm{Ek}}$ & Beda temperatur ekuivalen $(\mathrm{K})$ \\
\hline SC & $\begin{aligned} &= \text { Koefisien peneduh dari sistem } \\
& \text { fenetrasi }\end{aligned}$ \\
\hline SF & $=\underset{\left(\mathrm{Watt} / \mathrm{m}^{2}\right)}{\text { Faktor }}$ radiasi matahari \\
\hline $\mathrm{U}_{\mathrm{s}}$ & $\begin{aligned}= & \text { Transmitansi thermal fenetrasi } \\
& \left(\mathrm{Watt} / \mathrm{m}^{2} . \mathrm{K}\right)\end{aligned}$ \\
\hline$\Delta \mathrm{T}$ & $\begin{aligned}= & \text { Beda temperatur antara luar } \\
& \text { dan dalam (diambil } 5 \mathrm{~K} \text { ) }\end{aligned}$ \\
\hline
\end{tabular}

Formulasi ini untuk menghitung satuan unit atap, apabila lebih dari satu jenis bahan penutup atap, maka persamaan transmitansi thermal rata-rata seluruh luasan atap dihitung dengan mengalikan masing-masing luasan atap dengan nilai transmitan thermal dari berbagai bahan atap, kemudian dibagi dengan luasan total keseluruhan bidang atap. SNI mempertimbangkan RTTV ini dengan prosedur sebagai berikut pada gambar 2 .

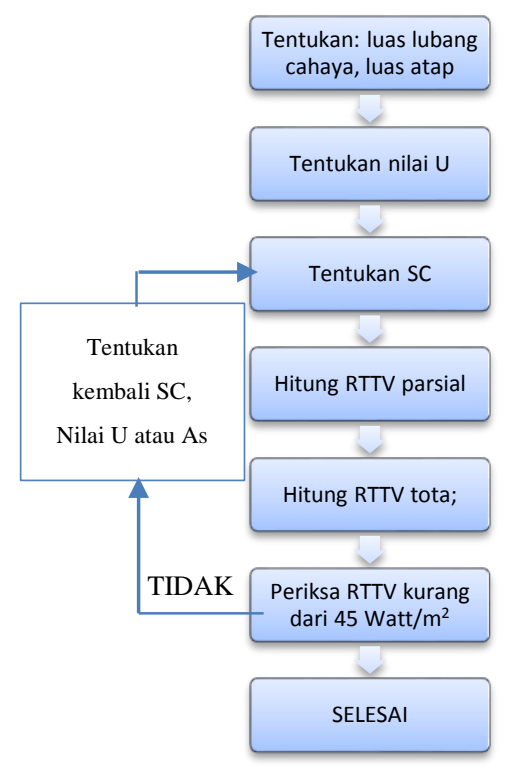

Gambar 2. Prosedur perhitungan RTTV.

Sumber: (SNI, 2000)

Berdasarkan formulasi dan prosedur SNI tersebut, sudah dapat dipastikan bahwa, nilai
RTTV berbanding lurus dengan nilai konduksi bahan dan nilai transmitan bahan atap bangunan. Oleh karenanya, dengan memandang bahwa sebuah bahan mempunyai nilai perpindahan panas maka tentu akan memberikan pengaruh terhadap efisiensi energi bangunan. Sehingga, dengan mengasumsikan untuk setiap bahan memiliki dampak panas, perlu dilakukan uji efisiensi bahan atap pada model eksperimen yang dilakukan pada penelitian ini.

Panas radiasi matahari yang dipancarkan sepanjang hari di daerah iklim tropis dapat menghantarkan panas bangunan pada bagian atap, dinding dan permukaan tanah. Penelitian yang berhubungan dengan perilaku panas bangunan mempunyai perhatian secara khusus pada kenyamanan thermal bangunan. Penilaian terhadap kenyamanan thermal ditentukan oleh empat faktor lingkungan yakni suhu udara, kecepatan angin, kelembaban udara, rata-rata suhu permukaan bahan bangunan serta dua faktor manusia yakni aktifitas dan pakaian (Satwiko, 2004). Lebih jauh faktor penentu yang dapat dilihat secara detil pada faktor lingkungan, bahwa suatu suhu permukaan bahan bangunan mempunyai kontribusi memberikan panas pada ruangan. Secara fisiologis, iklim mempengaruhi kenyamanan thermal bangunan gedung. Suhu dan kelembaban yang tinggi dari ciri khas iklim tropis lembab, menjadikan bangunan kurang nyaman ketika mengabaikan dampak suhu dan kelembaban lingkungan (Frick \& Mulyani, 2006). Bagaimanapun juga bangunan membutuhkan perlindungan dari radiasi panas matahari. Desain bangunan yang mengabaikan perlindungan panas pada bangunan akan membuat lingkungan semakin panas. Contohnya, apabila bahan yang digunakan tidak mampu melindung bangunan, bahan yang digunakan merupakan bahan konduktor panas, tentu akan membuat ruangan semakin kurang nyaman. Panas yang dirasakan di dalam ruangan bangunan juga akan dapat mempengaruhi panas ke lingkungan. Hal ini justru semakin menambah beban panas kawasan. Namun, ketika bangunan yang terasa panas dikondisikan dengan AC maka akan terjadi konsumsi energi dan akibat dari operasional AC juga mengakibatkan meningkatnya suhu lingkungan mikro. Hal 
yang paling bijaksana adalah menggunakan sistem pendinginan pasif yakni memanfaatkan potensi lingkungan secara alami melalui kontrol dan optimalisasi elemen alam.

Terkait dengan sistem pendinginan pasif, Francesco Barreca (Barreca, 2016) telah melakukan riset di daerah mediterania tentang atap yang dibuat dengan penutup tanaman dan atap yang tidak ada penutup tanaman. Hasil riset menyimpulkan adanya penurunan suhu yang cukup signifikan pada suhu ruang dalam di bawahnya.

Pada penelitian tentang atap hijau yang lain, diperoleh hasil bahwa bagian atap bangunan yang didesain dengan atap hijau berpotensi untuk digunakan menjadi bagian yang lebih bermanfaat yakni: mengumpulkan air hujan, mengurangi panas kawasan dan menjadikan daerah produktif pertanian yang dapat bermanfaat untuk keperluan pangan (Ugai, 2016). Penelitian ini sangat mendukung difungsikannya bagian atap bangunan untuk area yang dapat mengurangi beban panas ke lingkungan. Setidak-tidaknya, perletakan tanaman yang didesain pada atap memberikan kontribusi mendinginkan dan mengurangi penggunaan energi listrik untuk mengoperasionalkan alat pengkondisian udara seperti AC.

Dari aspek ekonomi bangunan, Faridah dkk menyatakan bahwa bangunan hijau didesain untuk berkontribusi pada perbaikan lingkungan, ternyata mempunyai nilai ekonomi yang efisien dalam jangka waktu panjang. Pembiayaan yang dikeluarkan untuk pembangunan gedung lebih kecil dibanding dengan nilai sustainabilitas bangunan dan kawasan (Faridah Muhamad Halil; Nasyairi Mat Nazir; Ahmad Azlee Hasan; Ani Saifuza Shukur, 2015). Dengan kata lain, efisiensi energi pada bangunan dapat dicapai dengan implementasi desain bangunan hijau yang berkonsep arsitektur ekologis. Salah satu konsep arsitektur ekologis adalah menggunakan bahan bangunan ramah lingkungan. Kriteria ramah lingkungan diantaranya dengan penggunaan bahan bangunan yang memberi beban panas lingkungan. Oleh karenanya, penelitian ini melakukan kajian terhadap beberapa bahan atap yang digunakan oleh masyarakat pada umumnya di perkotaan yang padat bangunan.

\section{METODE}

Penelitian ini merupakan penelitian kuantitatif yang menggunakan metode eksperimen nyata pada bangunan dengan ketinggian sedang di Kota Surakarta. Dalam penelitian ini membandingkan 3 (tiga) jenis bahan atap bangunan menengah hingga tinggi yang merupakan representasi dari bahan atap kebanyakan di Kota Surakarta.

Penentuan 3 (tiga) jenis bahan atap bangunan dalam penelitian diperoleh dari hasil pengamatan di Kota Surakarta. Penelitian memerlukan perbandingan untuk menarik hasil yang lebih mempunyai nilai variabel yang diteliti, sehingga mengambil 3 (tiga) perbandingan bahan atap bangunan. Variabel merupakan segala seuatu yang dapat berbentuk apa saja yang ditetapkan oleh peneliti untuk dipelajari sehingga diperoleh informasi tentang hal terkait dan dapat ditarik kesimpulan (Sugiono, 2017). Pada penelitian ini variabelvariabel meliputi berikut:

a. Variabel independent, yakni bahan atap bangunan terdiri dari atap beton, seng bergelombang dan galvalum.

b. Variabel dependent, merupakan suhu permukaan bahan atap bangunan

c. Variabel moderator, kondisi kecerahan langit, panas matahari.

d. Variabel intervening, yaitu kecepatan angin sekitar lokasi eksperimen.

Tahapan penelitian diawali dengan menentukan jenis bahan atap yakni dak beton, seng bergelombang dan galvalum. Masing-masing bahan diukur pada waktu yang bersamaan dengan alat ukur suhu permukaan infrared thermometer selama 30 detik setiap pengukuran. Waktu pengukuran ditentukan dalam tiga kurun waktu yakni pagi hari pukul 09.00, siang hari pukul 12.00 dan sore hari pukul 15.00. Pengukuran dilakukan selama 10 hari berturut-turut, pada cuaca yang cerah. Ketika hujan rintik pengukuran ditunda, namun ketika cuaca mendung pengukuran tetap dilaksanakan. Penetapan waktu pengukuran mempertimbangkan beban panas yang diprediksi mempunyai tingkat peningkatan dan penurunan yang tepat pada bahan atap bangunan, sehingga merupakan waktu ideal untuk mengambil data pengukuran. 
Tahapan pelaksanaan kegiatan penelitian diselenggarakan dengan sistematika penelitian seperti pada gambar 3 di bawah ini.

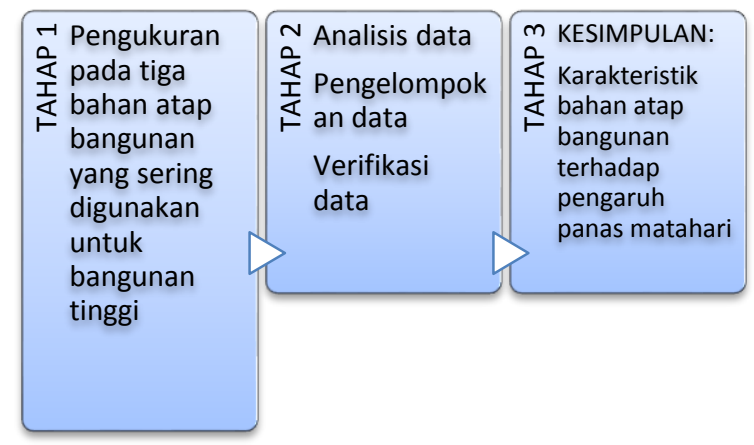

Gambar 3. Tahapan penelitaian.

Prosedur pengukuran suhu permukaan atap bangunan dengan alat infrared thermometer sebagai berikut:

a. Menyalakan alat dengan memencet tombol pelatuk.

b. Menyalakan sensor infrared, apabila layar LED tidak jelas dapat menyalakan lampu LED.

c. Mengarahkan sensor ke bagian permukaan bahan atap yang diukur, tekan beberapa saat dan tetap ditekan selama kira-kira 30 (tiga puluh) detik.

d. Pindah posisi alat ke bagian permukaan atap sisi yang lain dan lakukan pengukuran dengan cara yang sama. Satu bahan permukaan diukur berulang-ulang hingga mendapatkan dapat yang akurat.

e. Melakukan pengukuran di bahan atap yang berbeda dengan cara yang sama.

f. Pengukuran juga dilakukan pada bagian ruangan bangunan.

Data pengukuran diolah secara statistik untuk menemukan kesimpulan akhir yang dapat menunujukkan karakteristik suhu permukaan atap bahan bangunan. Kesimpulan yang diambil adalah menemukan kriteria bahan yang digunakan sebagai atap bangunan dengan klasifikasi sebagai berikut:

a. Bahan yang mampu menjadi isolator panas.

b. Bahan yang sensitif panas.

c. Bahan yang mudah memberikan efek panas dari radiasi matahari.
Dengan mengetahui karakteristik bahan tersebut akan dapat direkomendasikan bahan yang ideal untuk bangunan tinggi di daerah tropis agar tercapai efisiensi energi dan kualitas lingkungan yang baik.

\section{HASIL DAN PEMBAHASAN}

Sistematika penelitian mulai dari penentuan model bangunan menengah hingga tinggi melalui pengambilan sampel di sebuah kawasan permukiman padat di Kota Surakarta. Ada 3 (tiga) bahan yang secara umum digunakan untuk bahan atap bangunan tinggi di Kota Surakarta. Bahan penutup yang dominan adalah beton, seng bergelombang dan galvalum. Penelitian ini mengambil ketiga bahan atap bangunan tersebut untuk menjadi bahan eksperimen yang dipasang pada model.

Pertimbangan dalam penentuan model meliputi, ketinggian bangunan, kepadatan permukiman dan kriteria lokasi untuk dijadikan model. Model berada pada ketinggian 92 meter di atas permukaan air laut. Letak geografis pada $11045^{`} 15^{\prime \prime}-11045^{`} 35^{\prime \prime}$ Bujur Timur dan 70’ $36^{\prime \prime}-70^{\prime} 56^{\prime \prime}$ Lintang Selatan. Rata-rata daerah yang berada di -8 latitude/110 longitude ini memiliki potensi mendapat radiasi panas matahari sebesar 4,8 KWh. Lokasi berada di Kelurahan Jebres yang ditunjukkan melalui gambar 4.

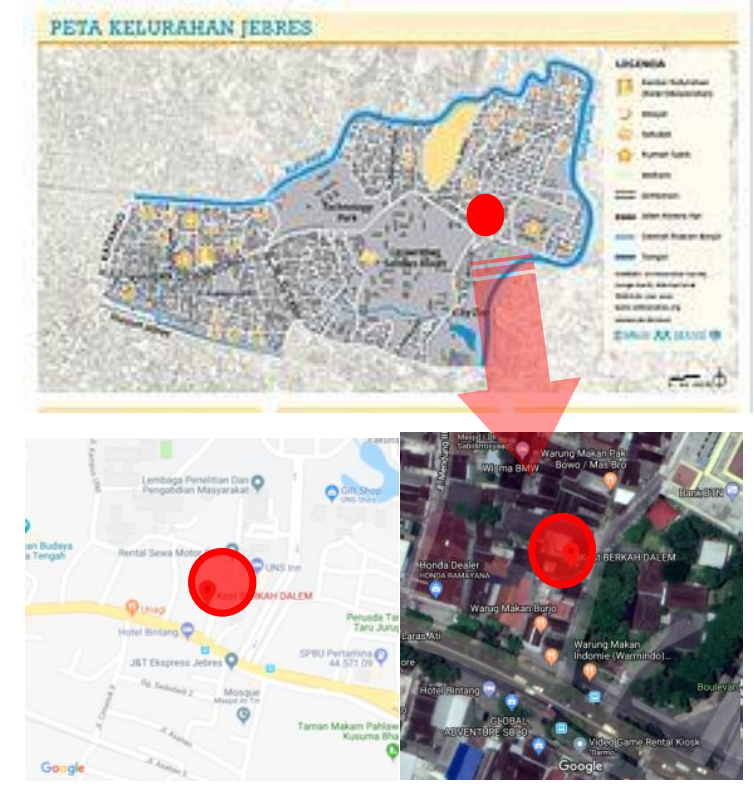

Gambar 4. Lokasi model eksperimen bangunan. Sumber: Google Map, diakses 28 April 2018. 
Lokasi obyek penelitian merupakan daerah tropis lembab yang pada saat pengukuran memiliki data cuaca di bulan Maret hingga April 2018 sebagai berikut:

Tabel 1. Data Cuaca Kota Surakarta Maret-April 2018

\begin{tabular}{|c|c|}
\hline Malam & $\begin{array}{l}23{ }^{\circ} \mathrm{C}-24{ }^{\circ} \mathrm{C} \text { kondisi langit cerah, } 97- \\
99 \% \text {, kec. Angin } 0-7 \mathrm{~km} / \mathrm{jam} \text { utara }\end{array}$ \\
\hline Pagi & $\begin{array}{l}23{ }^{\circ} \mathrm{C}-30{ }^{\circ} \mathrm{C} \text { matahari bersinar, } 68-89 \% \text {, } \\
\text { kec. Angin } 0-7 \mathrm{~km} / \text { jam selatan-timur }\end{array}$ \\
\hline Siang & $\begin{array}{l}28^{\circ} \mathrm{C}-31^{\circ} \mathrm{C} \text { kadang hujan rintik, } 64-77 \& \text {, } \\
\text { kec. Angin } 4-11 \mathrm{~km} / \mathrm{jam} \text { utara }\end{array}$ \\
\hline Sore & $\begin{array}{l}24^{\circ} \mathrm{C}-26^{\circ} \mathrm{C} \text { sebagian berawan, } 84-95 \% \text {, } \\
4-7 \mathrm{~km} / \text { jam utara }\end{array}$ \\
\hline
\end{tabular}

Sumber: BMKG mobile apps. (BMKG, 2018)

Model bangunan berada di lingkungan permukiman padat di pinggiran Kota Surakarta. Model bangunan berfungsi sebagai kost mahasiswi Universitas Sebelas Maret, sehingga bangunan ini merupakan bangunan hunian. Bangunan terdiri dari tiga lantai dengan pembagian ruang antar lantai yang berbeda. Lantai dasar digunakan kamar dan open space, lantai kedua untuk kamar dan ruang servis dan lantai ketiga untuk ruang kerja dan ruang komunal. Luasan model berkisar 15 meter panjang dan 7 meter lebar, dengan ketinggian bangunan hingga 12 meter, secara detil ditunjukkan pada gambar 5 .

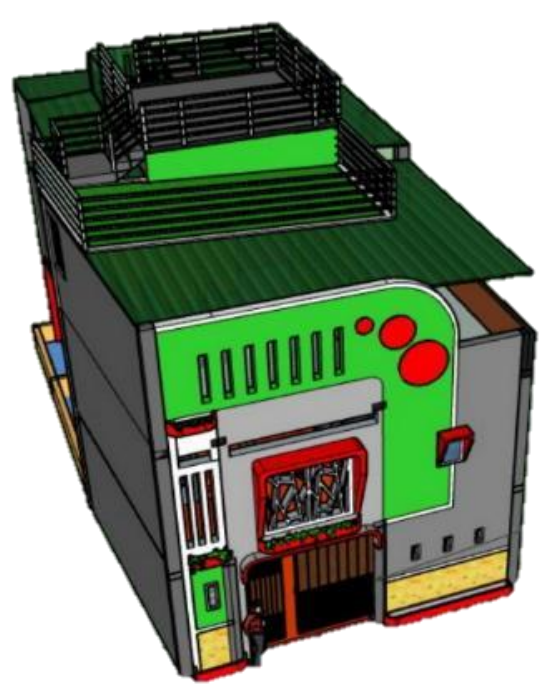

Gambar 5. Tampak depan model eksperimen bangunan.
Bagian atas bangunan dibagi bagi menjadi 3 (tiga) bagian yang masing-masing bagian menggunakan jenis atap berbeda, yakni: atap dak beton, seng bergelombang dan galvalum. Atap dengan bahan cor beton digambarkan dengan warna abu-abu. Atap dengan bahan seng bergelombang digambarkan dengan warna hijau terang. Sedangkan, atap galvalum digambarkan dengan warna hijau tua bergaris, seperti pada gambar 6 dan gambar 7

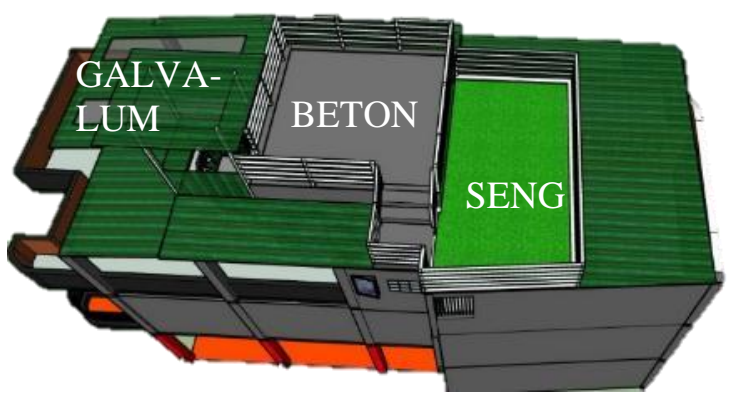

Gambar 6. Tampak atas dari selatan.

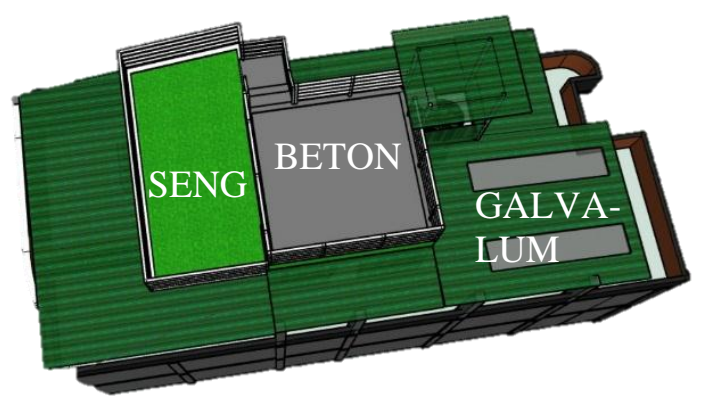

Gambar 7. Tampak atas dari utara

Pengukuran suhu permukaan diawali pada bulan April 2018 saat cuaca cerah dan sangat panas.

Sebelum dilakukan pengukuran, perlu memahami kriteria thermal pada bahan atap, yakni untuk beton mempunyai nilai absorbsi radiasi matahari 0,86. Bahan seng bergelombang yang digunakan sebagai atap pembanding mempunyai nilai absorbsi radiasi matahari sebesar 0,26. Sedangkan galvalum yang merupakan lembaran paduan alumunium mempunyai nilai absorbsi radiasi matahari sebesar 0,12. Sementara itu untuk nilai konduktivitas bahan bangunan beton ringan 0,303Watt $/ \mathrm{m} . \mathrm{K}$, sedangkan seng bergelombang dan aluminium yang merupakan paduan alumunium memiliki nilai konduktivitas bahan sebesar $211 \mathrm{Watt} / \mathrm{m} . \mathrm{K}$ (SNI, 2000). 
Hasil pengukuran menunjukkan angka yang terlihat jelas berbeda ketika pagi hari jam 09.00 untuk ketiga jenis bahan atap. Sementara pada sore hari pukul 15.00 suhu permukaan luar bahan menunjukkan angka yang tidak banyak perbedaan, seperti di lihat pada gambar 8. Pada pagi hari pukul 09.00 matahari bersinar cerah, suhu terendah adalah atap beton yakni $38,48^{\circ} \mathrm{C}$, sedang seng bergelombang dan galvalum relatif sama pada suhu $48.46{ }^{\circ} \mathrm{C}$ pada seng bergelombang dan $48.75{ }^{\circ} \mathrm{C}$ pada galvalum.

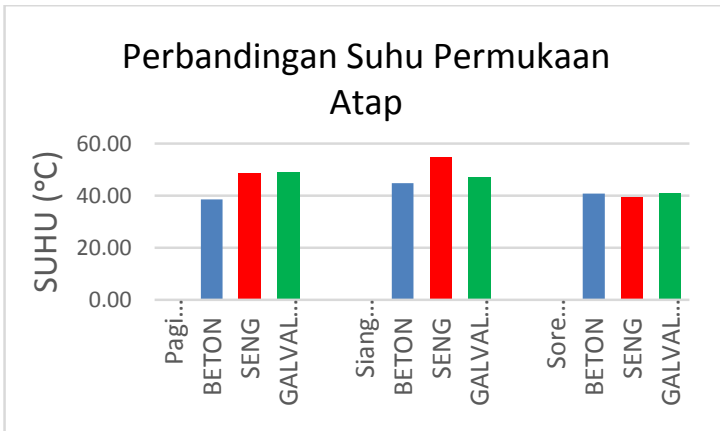

Gambar 8. Hasil analisis data pengukuran pada suhu permukaan luar bangunan.

Hasil analisis penggabungan mulai pagi hingga sore menunjukkan suhu rata-rata yang terpanas adalah seng bergelombang yaitu $47,48{ }^{\circ} \mathrm{C}$ sedangkan galvalum suhu rata-rata sepanjang hari mencapai $45,65{ }^{\circ} \mathrm{C}$ dan yang terendah adalah beton dengan suhu $41,37{ }^{\circ} \mathrm{C}$, seperti yang ditampilkan pada gambar 9 .

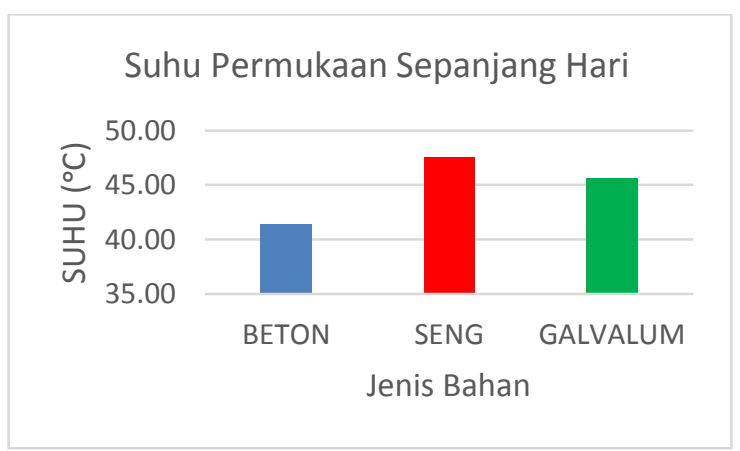

Gambar 9. Hasil analisis pengukuran suhu sepanjang hari pada atap beton, seng bergelombang dan galvalum.

Sementara, untuk hasil yang diperoleh pada suhu permukaan bagian dalam bangunan menunjukkan bahwa pada sore hari, terlihat perbedaan yang tipis antara ketiga jenis bahan atap bangunan. Pada pagi hari jam 09.00, beton mempunyai suhu yang paling rendah yakni
25,85 ${ }^{\circ} \mathrm{C}$ sedangkan galvalum mencapai suhu permukaan $44,23{ }^{\circ} \mathrm{C}$ dan seng bergelombang pada posisi tengah yakni suhu berkisar $39,68^{\circ} \mathrm{C}$. Untuk siang hari pukul 12.00, atap beton mencapai suhu $33,31{ }^{\circ} \mathrm{C}$ merupakan nilai terendah dari ketiga bahan. Suhu permukaan seng bergelombang pada capaian $42,68^{\circ} \mathrm{C}$ dan galvalum pada suhu tertinggi yakni $44,70^{\circ} \mathrm{C}$. Untuk perbandingan secara visual dapat dilihat pada gambar 10 .

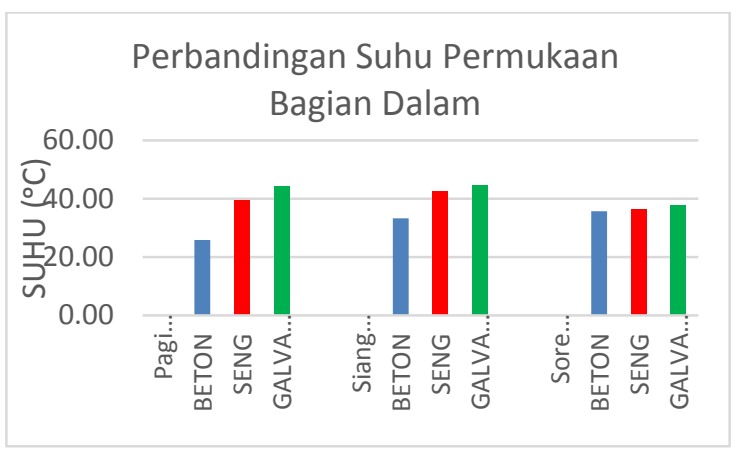

Gambar 10. Hasil analisis perbandingan suhu permukaan bahan pada bagian dalam ruang.

Dalam analisis lebih lanjut, data diolah untuk menemukan suhu rata-rata permukaan bahan bagian dalam ruangan. Hasilnya diperoleh bahwa pada sepanjang hari, beton memiliki kemampuan mempertahankan stabilitas suhu yang tinggi yakni dengan suhu $31,64^{\circ} \mathrm{C}$ yang merupakan suhu terendah. Seng bergelombang berada pada posisi menengah yakni dengan suhu $39,64{ }^{\circ} \mathrm{C}$ dan sensifitas tertinggi adalah galvalum pada suhu $42,28{ }^{\circ} \mathrm{C}$, seperti pada visualsisasi tabel gambar 11. Dengan demikian sensifitas beton paling rendah dan galvalum paling tinggi.

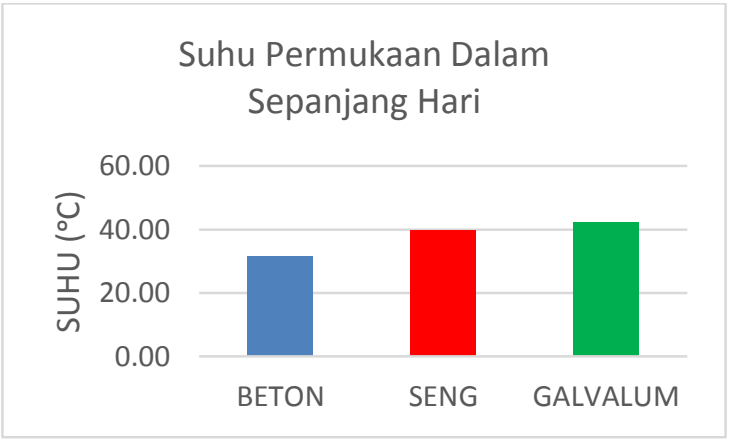

Gambar 11. Hasil analisis suhu permukaan bagian dalam.

Hasil akhir dari semua analisis disimpulkan melalui perhitungan rata-rata dari semua data pengukuran, yakni beton memiliki suhu 
permukaan paling rendah $36,5{ }^{\circ} \mathrm{C}$ pada sepanjang hari. Sedangkan seng bergelombang dan galvalum memiliki adaptasi suhu permukaan yang hampir sama, yakni $43,56{ }^{\circ} \mathrm{C}$ untuk seng bergelombang dan $43,96{ }^{\circ} \mathrm{C}$ untuk galvalum, lihat gambar 12 .

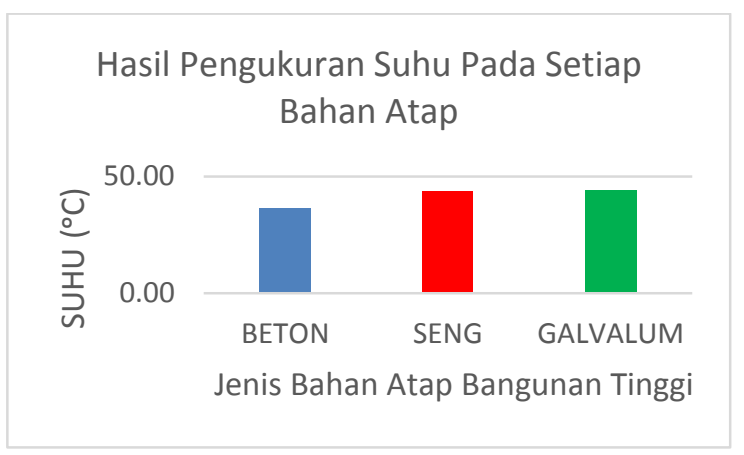

Gambar 12. Hasil analisis akhir perbandingan suhu permukaan antara beton, seng dan galvalum.

Gambaran lebih rinci tentang hasil pengukuran ditunjukkan melalui tabel 2, sebagai berikut:

Tabel 2. Rekap hasil pengukuran suhu permukaan bahan atap.

\begin{tabular}{lc}
\hline \multicolumn{1}{c}{ Bahan atap } & Suhu $\left({ }^{\circ} \mathbf{C}\right)$ \\
Beton & 36.50 \\
Seng & 43.56 \\
Galvalum & 43.96 \\
\hline
\end{tabular}

Yang menarik dalam penelitian ini, suhu permukaan untuk bahan atap seng bergelombang dan galvalum pada saat cuaca sangat cerah dengan pancaran radiasi matahari pada tingkat $7 \mathrm{~h}$ suhu maksimal $33{ }^{\circ} \mathrm{C}$ dengan RH 80\% kecepatan udara 9,3 km/jam dari arah ESE, diperoleh data pengukuran yaitu seng bergelombang pada suhu $61,8{ }^{\circ} \mathrm{C}$ sedangkan galvalum pada suhu $53,6{ }^{\circ} \mathrm{C}$. Angka ini menunjukkan suhu permukaan yang sangat tinggi pada suatu bahan atap bangunan. Oleh karenanya, bisa memungkinkan mempunyai nilai pancaran panas yang tinggi ke lingkungan sekitar. Dalam jumlah luasan yang semakin besar, tentu atap berbahan seng bergelombang dan galvalum sebaiknya diimbangi dengan perlakuan khusus yang dapat menurunkan suhu permukaan bahan sehingga dampak panas dapat direduksi. Sepertinya hasil temuan dari penelitian ini menarik untuk ditindaklanjuti dengan penelitian selanjutnya yang bertujuan untuk mengupayakan penurunan suhu permukaan bahan atap dalam bentuk modifikasi yang lebih ramah lingkungan dan tetap mengindahkan nilai estetika bangunan.

Secara menyeluruh, klasifikasi bahan atap bangunan dalam merespon radiasi panas matahari dalam penelitian ini dihasilkan sebagai berikut:

a. Bagian yang mampu menjadi isolator panas diantara bahan beton, seng bergelombang dan galvalum adalah bahan atap beton.

b. Bahan yang sensitif terhadap panas matahari dan cenderung mengalami perubahan suhu yang drastis adalah bahan seng bergelombang.

c. Bahan yang mudah memantulkan efek panas radiasi natahari adalah seng bergelombang dan galvalum.

d. Perbedaan karakter seng bergelombang dan galvalum adalah pada kecepatan adaptasi perubahan suhu. Seng bergelombang sangat cepat berubah dibanding galvalum.

Penelitian menghasilkan beberapa temuan, yakni dari ketiga bahan atap yang sering digunakan untuk penutup bagian atas bangunan, beton memiliki kemampuan isolasi panas yang paling tinggi. Sedangkan seng bergelombang memiliki kemampuan perpindahan panas yang tinggi.

Bahan seng bergelombang mempunyai sensifitas panas yang sangat responsif, ketika cuaca cerah dan radiasi panas matahari sangat tinggi, seng bergelombang juga mengalami kenaikan suhu permukaan secara cepat. Namun ketika cuaca meredup, mendung bahkan hujan, seng bergelombang pun cepat mengalami penurunan suhu permukaan. Hal ini juga terjadi pada dinamika suhu permukaan pada ruangan dalam. Bahan seng bergelombang memiliki karaktor konduksi panas yang tinggi.

Bahan galvalum, memiliki respon panas yang cukup tinggi namun mengalami penurunan yang sedikit melambat. Apabila sebuah bahan atap galvalum memiliki ketebalan yang sama dengan bahan atap seng, dimungkinkan perpindahan panas melalui konduksi pada bahan atap ini juga semakin berkurang. Suhu permukaan bahan pada area dalam bangunan sangat dipengaruhi oleh suhu permukaan 
bagian luar. Secara umum, berdasarkan data pengukuran di lapangan, bahan ini memiliki nilai konduksi panas tinggi.

Untuk aplikasi bahan atap pada bangunan tinggi, apabila menggunakan bahan seng bergelombang atau galvalum, sebaiknya menggunakan bahan peredam panas seperti alumunium foil, atau memberikan rongga atap untuk pergerakan udara, agar panas tidak dipancarkan ke dalam ruangan secara langsung. Sedangkan untuk aplikasi atap beton, sebenarnya area atap dapat dioptimalkan dengan memodifikasi dengan tanaman yang tahan panas sehingga radiasi matahari dapat direduksi dan pancaran panas bahan atap ke lingkungan berkurang. Pada penelitian selanjutnya, perlu mengembangkan hasil temuan penelitian dengan memodifikasi fungsi atap sebagai area peredam panas dan ramah lingkungan.

\section{KESIMPULAN}

Penggunaan bahan atap berpengaruh terhadap panas yang dipancarkan bangunan ke lingkungan sekitarnya. Pemilihan atap yang berkarakter mampu mereduksi panas merupakan pilihan yang tepat dalam penentuan bahan selubung atap bangunan di permukiman berkepadatan tinggi di daerah tropis. Kriteria atap yang mampu meredam panas merupakan upaya desain pendingan pasif yang berkontribusi untuk mengurangi suhu kawasan. Konsep ini merupakan konsep desain arsitektur ekologis yang ramah lingkungan sehingga perlu untuk diimplementasikan secara bersama dan terpadu.

Dari hasil penelitian, diperoleh data pengukuran yang menunjukkan bahan atap dak beton mampu meredam pancaran panas matahari dan mampu menjadi isolator panas pada ruangan bagian dalam. Hasil penelitian merekomendasikan atap beton untuk bangunan tinggi. Atap beton mempunyai karakter isolator panas yang baik dan mengurangi pancaran radiasi panas yang berlebihan.

Tentunya, hasil penelitian ini masih ada celah yang perlu diperbaiki sebagai temuan untuk merekomendasikan bahan atap pada bangunan tinggi yang sangat bermanfaat, dimodifikasi dan dikembangkan lebih jauh dengan aplikasi atap yang ramah lingkungan dengan memanfaatkan fungsi atap lebih banyak secara luas, diantaranya sebagai area hijau terbuka bangunan.

Penelitian mendatang yang berprospek dilakukan adalah penelitian modifikasi atap beton untuk kegiatan produktif dan ramah lingkungan. Hal ini penting dengan dasar pertimbangan bahwa nilai absorbtansi radiasi matahari yang tinggi dan nilai konduktan bahan menjadi nilai penentu dalam menghitung efisiensi energi bangunan tinggi. Di samping itu, juga perlu dipertimbangkan pantulan panas setiap bahan bangunan termasuk bagian atap, akan memberi dampak panas pada lingkungan yang pada akhirnya berdampak peningkatan panas kawasan (urban heat island).

Di sisi lain, penelitian menghasilkan temuan bahwa seng bergelombang dan galvalum merupakan bahan penutup atap yang mudah menjadi konduktan panas dan memiliki daya pantul panas yang besar. Penggunaan bahan seng bergelombang dan galvalum sebaiknya diimbangi dengan komponen lain yang mampu meredam panas baik dari interior maupun eksterior. Temuan bahan peredam panas di bagian interior sudah ada beberapa diantaranya penggunaan pelapis alumunium foil atau glasswool, namun untuk peredam bagian luar (eksterior) bangunan masih perlu ditingkatkan. Perlakuan peredaman panas bagian luar dapat dengan memodifikasi konstruksi atap, modifikasi fungsi atau bahkan peluang riset tentang bahan pelapis atap bagian luar.

\section{UCAPAN TERIMAKASIH}

Tim peneliti mengucapkan terimakasih kepada LPPM UNS, yang telah mendanai penelitian ini melalui Skema Penelitian Unggulan Terapan Dana PNBP Universitas Sebelas Maret Tahun Anggaran 2018 dengan nomor kontrak 542/UN27.21/PP/2018. Artikel ini merupakan produk luaran awal sebagai luaran tambahan yang nantinya akan dikembangkan dengan pembahasan lebih lanjut dan mendalam bertema model tata hijau untuk efisiensi energi bangunan tinggi di daerah tropis dengan konsep arsitektur ekologis. 


\section{REFERENSI}

Barreca, F. (2016). Rooftop Gardening. A Solution for Energy Saving and Landscaping Enhancement in Mediterranean Urban Areas. Procedia Sosial and Behaviour Science (pp. 720725). Reggio Calabria: Elsevier.

BMKG. (2018). Data Cuaca Kota Surakarta bulan Maret-April. Surakarta: BMKG.

Faridah Muhamad Halil; Nasyairi Mat Nazir; Ahmad Azlee Hasan; Ani Saifuza Shukur. (2015). Feasibility Study and Economic Assessment in Green Building. Procedia Sosial and Behaviour Science (pp. 56-64). Jakarta: Elsevier.

Frick, H., \& Mulyani, T. H. (2006). Arsitektur Ekologis. Yogyakarta: Penerbit Kanisius dan Soegijapranata University Press.

Satwiko, P. (2004). Fisika Bangunan 1. Yogyakarta: Penerbit Andi.

SNI. (2000). SNI 03-6389-200 Konsevasi Energi Selubung Bangunan pada Bangunan Gedung. Jakarta: Badan Standardisasi Nasional.

Sugiono. (2017). Metode Penelitian Kuantitatif, Kualitatif dan $R \& D$. Bandung: CV. Alfabeta.

Suryabrata, J. (2013). Current Problems and Possible Future Development. Green Design Education in Indonesia. Jakarta.

Ugai, T. (2016). Evaluation of Sustainable Roof from Various Aspects and Benefits . Procedia Sosial and Behavior Science (pp. 850-860). Honolulu: Elsevier.

Utami, D. A., Yuliani, S., \& Mustaqiemah, U. (2017). Penerapan Arsitektur Ekologis pada Sekolah Menengah Kejuruan Pertanian di Sleman. Arsitektura, 340348. 